\title{
A tropicália de Rogério Duarte em "Caetano Veloso" e "Gilberto Gil" (1968)
}

\author{
Rogério Duarte's Tropicália in "Caetano Veloso" and "Gilberto Gil" \\ (1968)
}

\section{ALMEIDA, Fernando dos Santos}

Universidade Federal de Santa Catarina - UFSC I fds.almeida@gmail.com

FUCHS, Isabela Marques

Universidade Federal do Paraná - UFPR I isa.fuchs@gmail.com

KAMINSKI, Rosane

Universidade Federal do Paraná - UFPR I rosane.kaminski@gmail.com

\begin{abstract}
Resumo
Este artigo consiste na decodificação da visualidade tropicalista de Rogério Duarte em suas duas peças gráficas: a capa do álbum "Caetano Veloso" (1968) e "Gilberto Gil" (1968). Através da análise formal e simbólica dos impressos, as capas de disco serão descritas a partir de uma abordagem tríplice, na junção de sua dimensão formal, semântica e históricosocial. Trabalhando em questões relativas à resistência cultural no Brasil em uma época efervescente e polêmica de ditadura militar, se pretende refletir as questões referentes a tropicália e em como Rogério Duarte trabalhou com seus conceitos: a busca por uma identidade nacional, o esvaziamento cultural, a resistência e a experiência política junto às massas.

\section{Abstract}

This paper consists on the decodification of Rogério Duarte's Tropicália visual aspects in two of his graphic works: the album covers of "Caetano Veloso" (1968) and "Gilberto Gil" (1968). Through a formal and symbolic analysis, the album covers will be described in a threefold approach: the junction of its formal, semantic and social-historical dimensions. By investigating the aspects related to cultural resilience in Brazil during a controversial and effervescent time of military dictatorship, we intend to reflect on questions about Tropicália and how Rogério Duarte worked with his concepts: the search for a national identity, the cultural emptiness, the resistance, and the political experience along with the masses.
\end{abstract}

Palavras-chave: Design e cultura. Design brasileiro. História brasileira. Tropicália.

Keywords: Design and culture. Brazilian design. Brazilian history. Tropicália. 


\section{INTRODUĈ̣̃O}

Outubro de 1967 no Teatro Paramount, na cidade de São Paulo: lá acontecia o III Festival da Canção da TV Record, um grandioso fenômeno da televisão brasileira da época, com números de audiência bastante expressivos. Seu sucesso, medido pelo número de telespectadores, também traduzo momento emblemático da história brasileira em que são produzidos e distribuídos bens culturais em volume, com o próprio Estado sendo o aparelho regulamentador e promotor da difusão desses bens, sendo repressor e incentivador das atividades culturais (ORTIZ, 1988, p. 116). Não é apenas a abundância de telespectadores que é importante, mas também quem estava no palco: Chico Buarque, Geraldo Vandré, Edu Lobo, Vinicius de Moraes, dentre outros nomes de relevância para a música brasileira. Entretanto, duas músicas soaram diferentes nesta ocasião: Domingo no Parque de Gilberto Gil e Alegria, Alegria de Caetano Veloso. Não ganharam prêmios mas propuseram algo novo: música pop, bossa nova, canção nordestina, tudo em uma verdadeira mistura que vinha junto de suas letras também inovadoras no meio musical (NAPOLITANO, 2001).

Uma música de tom leve, sereno e libertador, Alegria, Alegria trata de um jovem urbano, no coração do Brasil, sem lenço e sem documento. Também é uma música que trata da banalidade e do cotidiano: "Através de procedimento narrativo, as descrições de problemas sociais e políticos, nacionais ou internacionais, misturavam-se a índices da cotidianidade vivida por jovens de classe média, perdendo, assim, o caráter trágico e agressivo" (FAVARETTO, 1979, p. 8).

Oeu-lírico, portanto, seria um jovem pouco interessado na luta ideológica das notícias que ele via na banca de jornal: ele não queria ser engajado, ele só estava com preguiça e sem dinheiro, queria tomar uma Coca-Cola, pensava em tocar na televisão e ignorava um bocado a ideia do seu casamento'. O sujeito de Alegria, Alegria não é alguém fantasioso, mas inserido no contexto cultural brasileiro da época. Havia um aparente desinteresse de forma progressiva pela

Trecho da música "Alegria, Alegria": [...]/ O sol nas bancas de revista/ Me enche de alegria e preguiça/ Quem lê tanta notícia/ Eu vou/ Por entre fotos e nomes/ Os olhos cheios de cores/ O peito cheio de amores vãos/ Eu vou/ Por que não, por que não/ Ela pensa em casamento/ E eu nunca mais fui à escola/ Sem lenço, sem documento,/ Eu vou/ Eu tomo uma coca-cola/ Ela pensa em casamento/ E uma canção me consola/ Eu vou/ Por entre fotos e nomes/Sem livros e sem fuzil/ Sem fome sem telefone/ No coração do brasil/ Ela nem sabe até pensei/ Em cantar na televisão/ O sol é tão bonito/ Eu vou/ Sem lenço, sem documento/ Nada no bolso ou nas mãos/ Eu quero seguir vivendo, amor/ Eu vou/ Por que não, por que não. 
política, fruto da recusa² do projeto do período precedente (HOLLANDA, 1992, p. 65). O procedimento da mistura dá a tônica à música, em um procedimento que se assemelha à prática antropofágica de Oswald de Andrade (FAVARETTO, 1979, p. 9).

O LP de Caetano começou a ser gravado em 1967. A primeira música do álbum, ainda sem nome na época, inicia-se em um tom dramático enunciando a carta de Pero Vaz de Caminha e enfatizando ícones da cultura brasileira. Quando Luís Carlos Barreto ${ }^{3}$ ouviu a canção, sugeriu o nome: Tropicália. De acordo com Barreto, havia muita semelhança com a obra homônima de Hélio Oiticica, com seus cascalhos, plantas tropicais e televisões ligadas. Era a primeira vez que Caetano Veloso ouviu falar no nome do artista (VELOSO, 1997, p. 188).

A imprensa, então, criou um rótulo: tropicalismo ${ }^{4}$. Assim, tornava-se ainda mais fácil a aceitação dos tropicalistas pelo público jovem, iconoclasta, de classe média e que se identificava com a oposição à moral, bons costumes e demais valores da tradicional família brasileira mas que também não se sentia representado pelo engajamento da MPB nacionalista, tal qual Geraldo Vandré. A tropicália não era um movimento organizado e coeso, e sim um grupo formado por indivíduos que compartilhavam dos mesmos valores estéticos e políticos (NAPOLITANO, 2001 p. 65). Alguns temas básicos da discussão da tropicália são o retorno às origens do Brasil, internacionalização da cultura e volta às origens nacionais. A maior vitrine, de fato, era a música mas não podemos esquecer da audácia do Grupo Oficina, de Glauber Rocha, das montagens de $\mathrm{O}$ Rei da Vela, Roda Viva, da relevância de Oiticica e de suas experiências. Ou seja: o grupo tropicalista apresentou uma nova postura, uma nova forma de interação com o mercado de bens culturais em que, a partir de sua consolidação, a noção de nacional se transforma juntamente com seu processo de solidificação. Não obstante, a tropicália é uma peça emblemática na discussão entre arte engajada e arte alienada, ficando em um viés alternativo nessa dicotomia da época. Quanto a essa dualidade, Rogério Duarte afirma: “[...] nós não cabíamos nessa gaveta (da esquerda engajada) e fomos rejeitados por isso. O tropicalismo, e sua força, significa isso. Ele não é um movimento, mas um momento de um movimento que já começa muito antes" (COHN, 2005, p. 113).

2 A "recusa" a qual Hollanda aponta, pode dizer respeito também à "Grande Recusa" de Marcuse, uma negação total do status quo vigente, em uma rebelião contra os princípios morais dos dominadores. Ou seja, uma recusa ao sistema. (MARCUSE, 1966).

3 Fotógrafo jornalístico e produtor de cinema, responsável pela produção de Vidas Secas, Terra em Transe, entre outros.

4 Decide-se trabalhar com o nome tropicália sem maiúscula em vez de "Tropicália" ou "tropicalismo", em uma adoção ao pensamento de Torquato Netto: “Essa história de 'ismo' [...] reduz a coisa a uma coisa momentânea, e a Tropicália é uma coisa de repercussão enorme, além do prazo" (TORQUATO NETO, 1972). 
A sua ligação direta com a cultura de massa criou um novo espaço para experimentação e comunicação: no alinhamento entre a novidade e a cultura de massa, criou-se um "momento de avanço" (COELHO, 2010, p. 39).

Em 1965, dois anos antes de projetar a capa do disco homônimo de Caetano Veloso, Duarte escreveu o artigo "Notas sobre o desenho industrial", no qual critica e discute justamente a normatividade modernista que seria proposta no design brasileiro - a mesma que foi realizada por Villela em suas capas (DUARTE, 1965). Ele definitivamente não queria que a tradição gráfica suíça, repleta de operacionalismo científico e rigor funcional e estético, virasse um dogma no Brasil. Em uma tentativa de explicar o que seria, de fato, o design - ou desenho industrial, uma terminologia nova em terras brasileiras -, Duarte sintetiza: "ideação de formas para produção em série". Ponto. E como grupos de existências, um produto industrial seria uma existência e uma ideia, as duas coisas ao mesmo tempo, criando a reciprocidade entre qualidade e quantidade. Um contato operatório entre sujeito e objeto acontece no momento em que o indivíduo toma em suas mãos o objeto que foi desenvolvido, em uma relação consumatória ou, até mesmo, antropofágica. Este texto desenvolve uma linha argumentativa fundante sobre a estética tropicalista e a estética pós-moderna em solo brasileiro, nas suas postulações quanto à ruptura entre dualidades indústria-arte e erudito-popular, sendo um texto de grande relevância para o entendimento das relações entre design e sociedade no Brasil (TEIXEIRA, 2012). Justamente no exercício de ruptura realizado por Rogério Duarte na capa do Caetano Veloso (que, por sinal, foi seu primeiro projeto gráfico destinado à uma capa de disco) que cabe-nos discutir a postura estética brasileira da pósmodernidade. O moderno, ligado a uma proposta de desenvolvimento, perdeu o sentido. Afinal, é possível impulsionar a modernidade cultural quando a modernização socioeconômica é tão desigual? (CANCLINI, 1997). A heterogeneidade no discurso cultural do pós-modernismo corresponde diretamente à tropicália (HARVEY, 2001, p. 9). Como Rogério Duarte assume,

[...] minha visão era bem pós-moderna, no sentido de que eu não estava contestando o passado, mas queria incorporar tudo. Quando começamos a estudar profundamente uma coisa e refletir sobre ela, só assim podemos estabelecer uma ruptura. Qualquer ruptura baseada no desconhecimento é uma pseudo-ruptura. Veja os músicos do serialismo, da dodecafonia, como Schoenberg, que era professor de harmonia tradicional (RODRIGUES, 2007).

Esse contato sugerido por Rogério Duarte merece uma reflexão e um alinhamento. O design gráfico é a atividade relacionada à elaboração de projetos para reprodução por meio gráfico de peças expressamente comunicacionais (VILLAS-BOAS, 2000). Ou seja, transmitir uma mensagem, decodificá-la. 
Fazê-la falar. A grande questão é que as imagens são dotadas de vida, e não elementos estáticos à mercê do universo: são organismos dotados de desejos (RANCIÈRE, 2015).

Vamos retornar ao disco de Caetano Veloso (Figura 1). Suas composições que tratam da brasilidade, do desejo pela modernidade, do vazio cultural, do cotidiano e da cultura jovem são sui generis na música brasileira da época. Porém, não é só isso que exprime singularidade: temos a sua capa.

Figura 1 - Capa do disco "Caetano Veloso" (1968), com projeto gráfico de Rogério Duarte.

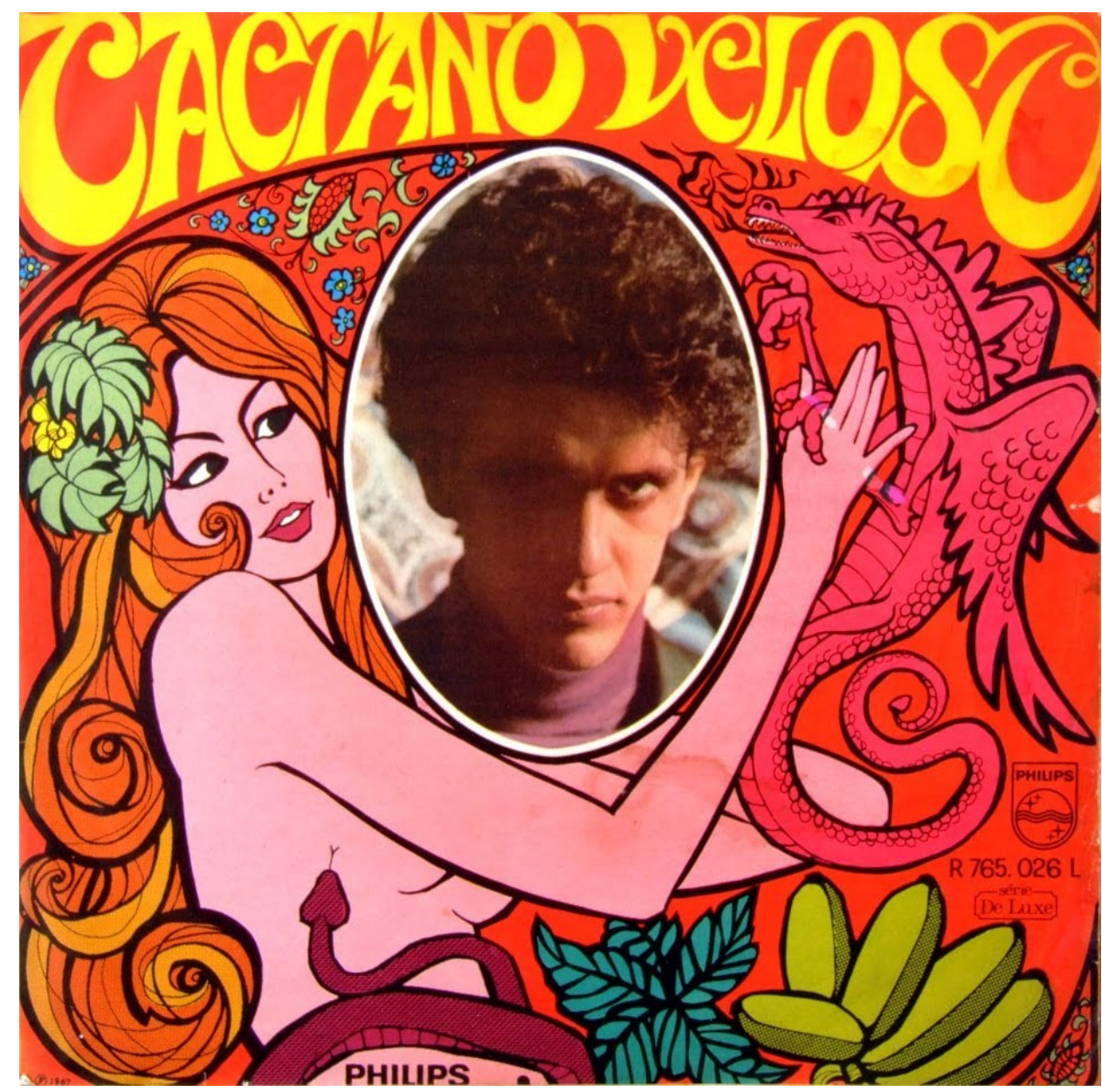

Fonte: Mello (2006).

Caetano ouviu o nome Rogério Duarte repetidas vezes na Faculdade de Filosofia da Bahia, geralmente entrelaçado aos comentários a respeito de sua "inteligência inqueta e pouco convencional" (VELOSO, 1997, p. 106). A capital baiana, célula mater da tropicália, foi palco de encontros de diversos intelectuais e artistas nos anos 1960 e 1970, tornando-se uma espécie de epicentro da produção cultural do Brasil. Quanto ao seu encontro com Duarte, Caetano descreve que: 
[...] quando cheguei ao Rio com Bethânia, em 64, Rogério apareceu no Teatro Opinião e, ao fim do espetáculo, saímos para conversar. Nada do que me tivessem dito sobre ele na Bahia poderia ter me dado a medida da impressão que ele me causou. Sua voz era mais potente, sua mente mais rápida e suas ideias mais desconcertantes do que eu teria sido capaz de imaginar. Havia entre ele e seus discursos um comprometimento a um tempo visceral e metafísico que multiplicava o poder persuasivo dos argumentos. E ele era surpreendentemente gentil e amigável. Foi carinhoso e irônico por estar tratando com baianos um tanto mais novos do que ele, e a gente sentia que era por estar comovido que ele idealizava uma nossa suposta pureza dizendo: 'Vocês não são neuróticos, vocês são diferentes daquela gente do meu tempo na Bahia'. Isso não o impedia, no entanto, de dinamitar nossa ingenuidade com tiradas politicamente blasfemas. Ele parecia a um tempo querer nos resguardar de um certo cinismo amargo que a vida já lhe tinha ensinado, e nos alertar contra a adesão inocente ao ideário dominante nos meios intelectuais (VELOSO, 1997, p. 24).

Indo além da uma relação de amizade, empatia e diálogos que se desenvolveu nos idos dos anos 1960 entre eles, Rogério Duarte desenvolveu o projeto gráfico do disco Caetano Veloso de 1968. Ao centro da ilustração, o rosto do cantor com um olhar penetrante em uma sombra dura, inserido em uma figura ovalada. A escrita art nouveau do seu nome na parte superior da capa destaca-se, mas não tanto quanto as outras figuras repletas de simbologias: a serpente, as folhas, as bananas, o dragão, a mulher nua e as flores. Em um exercício kitsch, os elementos estético-formais são coloridos, exuberantes, fortes e vívidos. A estética antropofágica está justamente aí: no exercício do cafona, da hipérbole e do alinhamento anacronismo/modernização. Cabe uma redescoberta do Brasil também em um plano estético-visual, na revivência dos arcaísmos brasileiros (FAVARETTO, 1997), gerando um procedimento de mistura em que o vernacular soma-se ao psicodélico, transformando-se em um pastiche visual (RODRIGUES, 2007).

O exercício de uma busca da autenticidade brasileira - a busca das relíquias do Brasil - dá-se em um plano de construção simbólica, tendo em vista que não há uma única identidade brasileira inserida em uma resposta irredutível, mas sim uma história da trajetória da ideologia da cultura brasileira (ORTIZ, 1988, p. 183). A história do Brasil é a de uma nação em processo, em uma busca de autoconhecimento e de transformar-se em conceito (IANNI, 1996). A antropofagia oswaldiana, a busca pelo sabor da gente brasileira, das paisagens, dos retratos do Brasil; a busca, a mesma da tropicália, que adotou a proposta do canibalismo cultural proposto por Oswald de Andrade e transformava lixo comercial em criações autênticas, poéticas e fluidas (VELOSO, 1997, p. 170). 
A capa, portanto, vai perdendo seu caráter meramente funcional, de proteção, de envoltório, para se tornar um suporte de veiculação de ideias (MATTOS, 2003). Nessa proposta de exercício de um design vinculado à uma visualidade barata, entra um conceito estético bastante disseminado: o mau gosto. O bom gosto, este tido como burguês, mesquinho, limpo, frio, branco, era rejeitado na prática de Duarte, em uma oposição à seriedade da MPB e da bossa nova, em uma crítica aos valores sociais e retrógrados do âmbito cultural e social do Brasil do final dos anos 1960 (DUNN, 2009, p. 147). A postura tropicalista reduzia a cultura popular ao simplismo estético e seu exercício do uso de elementos exóticos, cafonas e kitsch era justamente para "desqualificar a possibilidade de uma arte engajada e nacionalista" (NAPOLITANO, 2010). A discussão entre o popular e o nacional neste caso se amplifica para a questão da cultura popular de massa, desenvolvendo uma gama de redefinições.

Vale lembrar a experiência estética de César Villela nos discos da Gravadora Elenco (Figura 2): sua composição era sistemática e identificável: a foto do artista em alto contraste, três círculos vermelhos e uma intervenção no nome do artista. "Concisão", "objetividade" e "racionalidade" seriam subjetivos caracterizantes da visualidade das capas da bossa nova (NAVES, 2001):

Figura 2 - Capa do disco "Vinicius e Odette Lara" projetado por César Villela (1963).

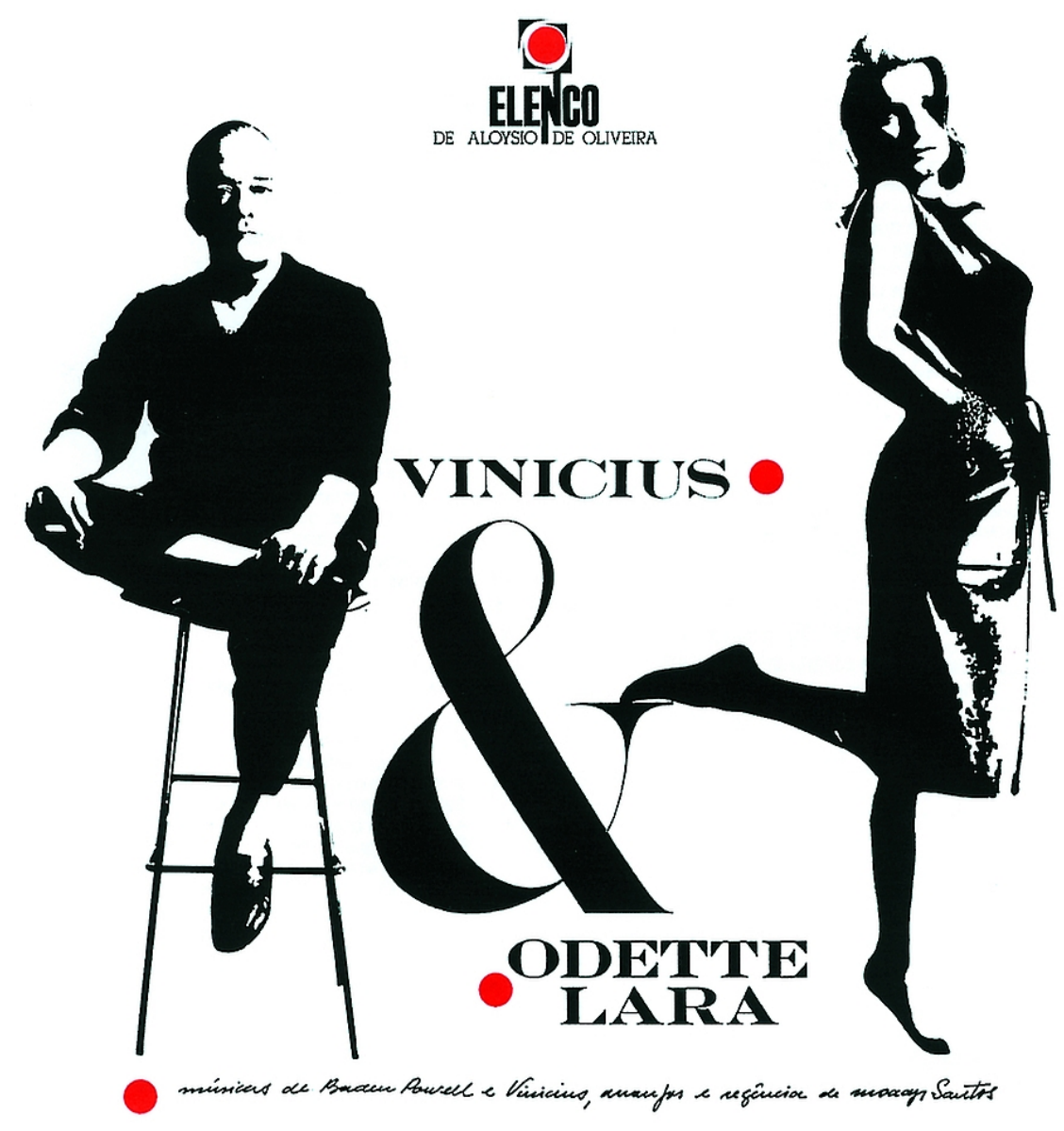

Fonte: Mello (2006). 
O olhar penetrante de Caetano ao centro superior da peça nos fornece o que Mitchell chamaria de expressão direta de desejo pictórico (MITCHELL, 2015). A seriedade e a dureza da expressão do artista não são simples e caladas, mas provocadoras. Não há frieza na fotografia, mas sim a inquietação. E se destaca visto que está centralizado em uma ilustração extremamente saturada e eufórica. Este modo um tanto quanto grosseiro de constituição da imagem, em que há um chamado e o efeito "emerge de um encontro intersubjetivo composto por signos de desejo positivo e traços de falta e impotência" (MITCHELL, 2015) é usado em diversos meios (a publicidade, por exemplo).

A maior problemática é que este projeto não foi feito para contemplação. Não é uma ilustração que está exposta em uma galeria e que poderá, no máximo, ser reproduzida em souvenirs ou em bolsas e cadernos. Estamos falando de um projeto industrial, reproduzido em escala industrial no mesmo suporte, e será vendido em inúmeras lojas de disco ou demais estabelecimentos comerciais. $\mathrm{O}$ que acontece é a criação de um signo de identificação. O projeto desenvolvido por Duarte é facilmente identificável como sendo aquele disco do Caetano. Seja por suas cores, pela sua vivacidade ou pela sua totalidade. Ou mais: pela sua novidade, se formos pensar no contraste existente entre a capa de Caetano Veloso e as demais capas da MPB da época. Essa capa sugeria algo de novo na música brasileira sem você ter ao menos ter reproduzido o disco. Pois, assim como o desejo lacaniano, "a essência do tropicalismo era um desejo amoroso de modernidade para o Brasil" (COHN, 2009).

\section{A MELANCOLIA, O POP, O DEBOCHE, A MARGINÁLIA: "GILBERTO GIL" (1968)}

O olhar derrotista e pessimista do final dos anos 1960 é evidente. Havia uma grande fervura cultural mas também uma espécie de derrotismo, de frustração. Juntamente com "a sensação de isolamento político que se abateu sobre os setores nacionalistas" (NAPOLITANO, 2011, p. 42), desenvolveu-se uma maior autonomia dos artistas da época, devido às estruturas partidárias fragilizadas. Em contrapartida, isso significou ficar dentro de seus espaços autorizados e com um comportamento exemplar. Ou seja, era melhor não existir conteúdo crítico. Não havia liberdade, mas uma falsa sensação da mesma; dizer que a censura só começou depois do Al-5, em final de 1968, é uma falácia. As manifestações contra o "obscurantismo e terror cultural" datam dos primeiros anos da Ditadura, em que falavam abertamente também quanto a libertação de presos políticos e tortura (MANIFESTO..., 1965). A violência militar não começou no Al-5, mas desde os passos iniciais do Golpe, sobretudo no campo cultural, onde o terror foi instalado (CONY, 1964, p. 90). A Ditadura era não apenas truculenta, mas também interesseira: há uma ponte entre os interesses militares e o dos grandes capitalistas, afinal, os interesses deles são os mesmos. Nisso, há a junção da ideologia moralista com a mercadológica (ORTIZ, 1988). 
É nesse ano, com a sua violência e truculência em expansão conectados à tensão entre a sociedade brasileira e o regime militar, que se cria um canal ideal entre cultura e projeto político revolucionário (COELHO, 2010, p. 39). Gilberto Gil lança seu álbum homônimo em 1968. Quando Zuenir Ventura elucida esse ano como sendo o que não acabou, ele fala justamente do quão simbólico este ano é para o cenário cultural e político do Brasil, como 1968 ainda é presente no imaginário coletivo, mas muitas vezes não com um olhar de reflexão (VENTURA, 1988). Seu conteúdo imaginário e sua força identitária tornam 1968 não apenas um ano, mas algo mítico e sinônimo de juventude, rebeldia, vivacidade e multiplicidade nos debates políticos (D'ARAÚJO; SOARES, 1994, p. 17).

Junto com Antônio Dias, artista plástico, e David Drew Zingg, fotógrafo, Rogério Duarte desenvolve o projeto gráfico da capa de Gilberto Gil em 1968 (Figura 3). Duas palavras são fulcrais na visualidade proposta: o pop e o deboche.

Figura 3 - Capa do disco "Gilberto Gil" (1968), com projeto gráfico de Rogério Duarte.

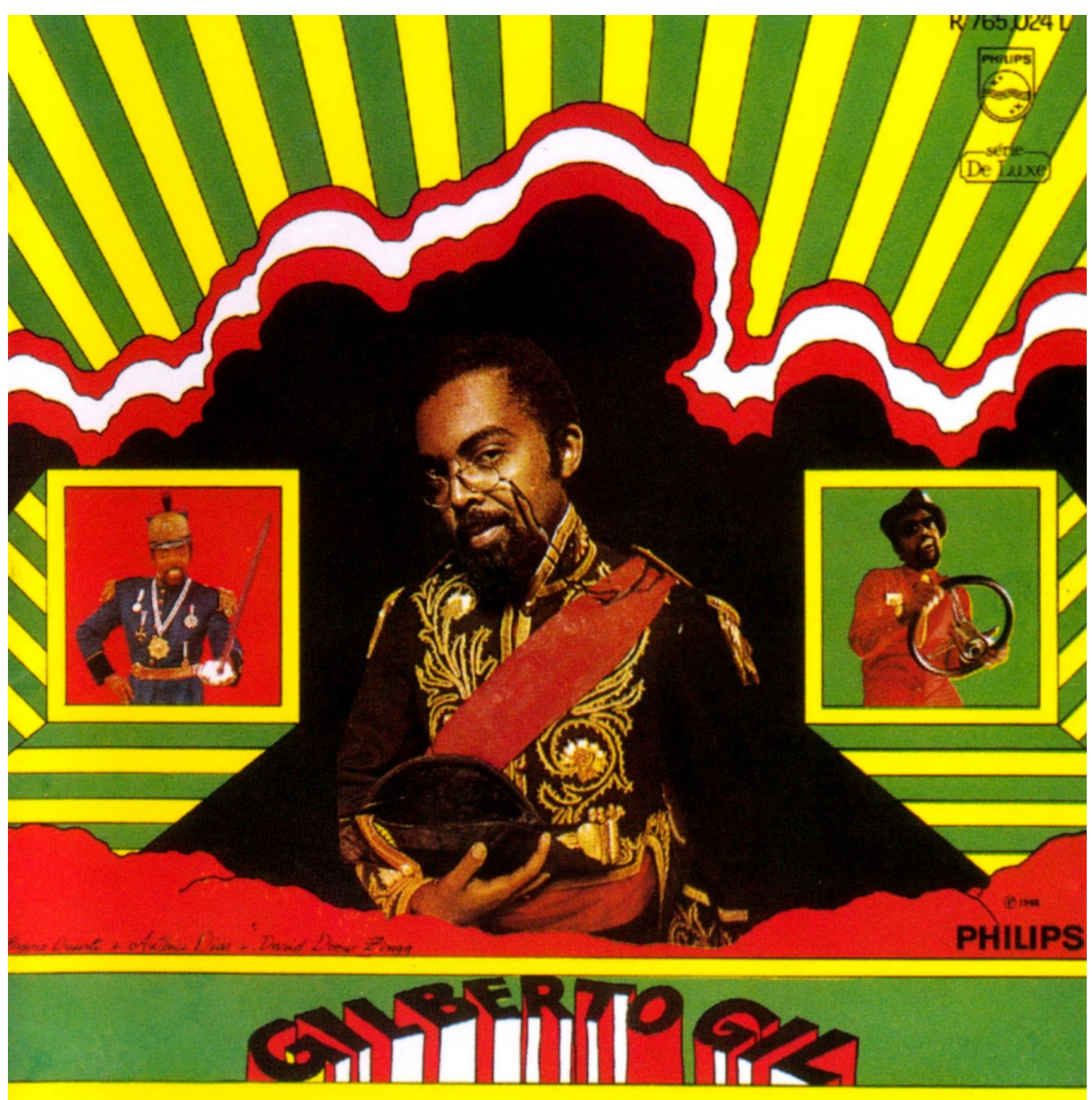

Fonte: Mello (2006). 
A capa é totalmente irreverente. Em destaque, Gil nos lança um olhar sereno ao portar o fardão da Academia Brasileira de Letras. Nas laterais, inseridas em quadrados que se projetam em linhas retas amarelas e verdes, Gil dá um sorriso forçado típico de fotografia ao segurar uma espada vestido de militar, e na foto à direita com um volante na mão, chapéu na cabeça e um óculos no rosto, representa um possível motorista debochado. A ilustração que permeia toda a capa tem toda uma essência de revista de super-herói, com o nome do cantor sendo projetado para o alto. As cores mega-saturadas são apenas três: amarelo, verde e vermelho. As linhas retas "estridentes" ao topo sugerem urgência, como um efeito de radiação, em que "elementos são girados para criar um formato composto radiado a ser usado como uma superunidade de forma ou para estabelecer uma composição formal exibindo uma estrutura de radiação subjacente" (WONG, 2001, p. 18). Abaixo das linhas, há uma composição branca e vermelha que se assemelha à nuvens densas. Abaixo, formas abstratas vermelhas semelhantes à uma representação topográfica.

O procedimento de repetição de formas e figuras se conecta diretamente à estética pop. A música pop foi tomada como referência pela tropicália. As possibilidades de criação entre o alinhamento da música importada e outros elementos, como o berimbau, geravam efeitos artísticos ricos para uma crítica à música brasileira. Assim, evidenciavam-se os muros do confinamento cultural brasileiro. O contraste da sonoridade cosmopolita e urbana trazida pelo pop e deglutida pela tropicália funciona como uma provocação e questionamento quanto ao arcaico da cultura brasileira. O pop é um dos responsáveis pela vitalidade tropicalista, ao mesmo tempo em que questiona questões referentes à sociedade do consumo (FAVARETTO, 1979, p. 28).

Evidentemente, o pop se expande para a área visual. A nomenclatura iniciou-se no campo das artes visuais, em uma busca pela discussão sobre a cultura de massa, a cultura de consumo, do universo programado por imagens, da propaganda, do mundo das embalagens, revistas e HQ's (FARTHING, 2010, p. 484). Artistas brasileiros como Claudio Tozzi ${ }^{5}$ e Teresinha Soares ${ }^{6}$ se alimentavam dessa mesma estética utilizada por Rogério Duarte; as cores intensas e contornos pesados, como se tudo tivesse saído de uma história em

5 Artista plástico que manifestava questões a respeito da ditadura militar, do cotidiano e da violência em suas obras, como a pintura "Che" (1967). O resultado do seu trabalho despertava a atenção da mídia pelo seu conteúdo "semi jornalístico" e seu viés comunicacional e questionador (Giovanetti, Bruno; Kiyomura, Giovana. "Um Artista na Multidão". In.: Giovanetti, Bruno; Kiyomura, Giovana (org.) Claudio Tozzi. São Paulo: Edusp.

6 Teresinha Soares é uma artista mineira que desenvolveu trabalhos com um viés crítico ao estatudo da violência, ao consumo e ao machismo institucionalizado no Brasil. Uma obra bastante emblemática de sua autoria é o quadro "Guerra é Guerra - Vamos Sambar" (1968), que se caracteriza pelas cores fortes, traços grossos, e representação sintética da violência, do nacional e, principalmente, o contraste entre o ufanismo e a escuridão do período (SANTOS; VIVAS, 2014) 
quadrinhos da banca de jornal. A visualidade pop se alimenta, portanto, de um lúdico mesclado à uma tônica crítica ao consumo. Quando se trata de Brasil, se fala de uma linguagem importada; o debate se transforma e vai para o âmbito do antropofágico e de assumir o subdesenvolvimento e as crises sociais do período.

Duarte também se apropria do deboche como recurso estético. Primeiro que é necessário uma certa dose de coragem para vestir uma farda militar do Brasil Império em um disco de música comercial. Não só isso, mas o conteúdo das músicas do álbum de Gil são agressivas e certamente que iriam sofrer uma recusa por parte do governo. Em Marginália II, por exemplo, fala-se do Brasil como fim do mundo, da fome e da bomba ${ }^{7}$. Domingo no Parque, música que ficou célebre junto com Caetano Veloso no III Festival da Canção, já era dissonante por si só e com sua composição elétrica; já causaria estranhamento.

É na alegoria da tropicália que se expressam os conjuntos de tensões políticas e culturais da sociedade brasileira urbana do período (NAPOLITANO, 1998). Em um jogo de acha/esconde, o enigma da alegoria é uma artimanha diante da censura, a realização de um ato proibido com cara de permitido (XAVIER, 2012, p. 462). A ironia era constante no exercício tropicalista: na zombaria com os emblemas nacionais, rejeitavam-se as fórmulas prontas para produzir uma cultura nacional única e autêntica. O deboche expressa criticamente questões polêmicas relativas ao espaço social em um tom bem humorado para então ser percebido o seu absurdo pelo grande público. Assim, desloca o acento e permite a reconstrução do reprimido (FAVARETTO, 1979, p. 84). Claramente, é um equívoco considerar que tal atitude seria demarcadora de um antinacionalismo ou vontade de se distanciar da cultura brasileira por parte do exercício tropicalista (DUNN, 2009, p. 95). É no seu tom pessimista e amargo que nasce, em contraponto, o humor. Se fosse por um tom pessimista, de negação e de derrota, muito mais óbvio e dentro do lugar-comum seria se Duarte fizesse uma capa sóbria e entristecida. Só que esse não é o caminho que a tropicália segue, nem em sua musicalidade, nem em sua visualidade. Como nos diz Caetano,

[...] sentíamos que o país ter chegado a desrespeitar todos os direitos humanos, sendo um fato consumado, poderia mesmo ser tomado como um sinal de que estávamos andando para algum lugar, botando algo terrível para fora, o que forçava a esquerda a mudar suas perspectivas. Nós não estávamos de todo inconscientes de que, paralelamente ao fato de que colecionávamos imagens violentas nas letras das nossas canções, sons desagradáveis e ruídos 
nos nossos arranjos, e atitudes agressivas em relação à vida cultural brasileira nas nossas aparições e declarações públicas, desenvolvia-se o embrião da guerrilha urbana com a qual sentíamos, de longe, uma espécie de identificação poética (VELOSO, 1997, p. 100).

Essa discussão se desloca para o campo da autoria. Seria possível dizer que Rogério Duarte é o único signatário de sua peça gráfica? Que apenas ele, junto ao fotógrafo e o artista plástico, produziu e desenvolveu toda essa visualidade? Encara-se essa pergunta tomando Rogério Duarte como um dos grandes responsáveis pela visualidade da tropicália (junto com designers e artistas como Rubens Gershman e Alain Voss, para citar alguns nomes, responsáveis pelas capas de "Tropicália" e "No País dos Baurets", respectivamente). Primeiramente, o designer não tem por definição um estilo individual, uma visualidade própria. 0 designer busca, por essência uma solução projetual de forma materializada. No caso de projetar uma capa para o álbum de Gilberto Gil, a diretriz seria materializar visualmente as composições musicais que estão inseridas no disco. Nisso cabe o designer interpretar, investigar, se inserir, questionar e perceber. No final das contas a autoria em design se relaciona junto ao cliente que encomendou o projeto, peça fundamental na intermediação desse processo. No final das contas, não dá para alegar que há apenas um produtor de tal visualidade, mas sim que há uma autoria coletiva (VILLAS-BOAS, 2000).

A relação cliente-designer entre Gilberto Gil e Rogério Duarte se dá de uma forma totalmente diferente da rotineira, em que o designer é um desconhecido que trabalha em um estúdio ou em um escritório e é procurado pelos seus bons projetos. Eles já se conheciam e já tinham um envolvimento ideológico e de amigos em comum já fazia tempo. Rogério Duarte saiu de Santa Teresa, no Rio de Janeiro e se mudou para o Solar da Fossa (VELOSO, 1997, p. 117), pensão que abrigava Torquato Netto, Caetano Veloso, Gilberto Gil, Ruy Castro, entre vários outros nomes da cultura brasileira. O contato entre os dois se deu de forma bastante íntima e frutífera, artistica e ideologicamente falando.

1968, novamente, o ano que não acabou. As lutas estudantis nesse ano tomaram força e vigor, culminada na morte do estudante secundarista Edson Luís, morto pelos militares em abril deste ano. A sua missa de sétimo dia na Igreja da Candelária se tornou um símbolo. Símbolo da inescrupulosidade militar e da resistência (D'ARAÚJO; SOARES, 1994, p. 22). A missa foi vigiada e reprimida por tropas policiais à cavalo, com a consequente prisão de pessoas que estavam a assistindo. Entre elas, Rogério Duarte e seu irmão, Ronaldo. Ao final do ano, em 22 de Dezembro, Caetano e Gil são também presos. Aqui, inicia-se um hiato que só começa a ser retomado em 1971.

Caetano e Gil sabiam que mexiam com coisas perigosas. Havia, de fato, um poder subversivo na tropicália, sendo os tropicalistas grandes inimigos do regime; eles estavam na mídia, eram adorados, mas também eram agitadores. 
Essa linha de limite era justamente a questão de inquietação dos militares: isso era muito mais perigoso do que canção engajada e protesto explícito (VELOSO, 1997, p. 401). A área cultural no AI-5 foi profundamente afetada,

\begin{abstract}
[...] afinal tratava-se de um momento em que a Doutrina da Segurança Nacional cristalizava-se como o principal instrumento norteador das ações de Estado e, nesse sentido, caberia uma maior intervenção deste nos diversos campos em que estava dividido o 'poder nacional', dentre estes o 'poder psicossocial'. Outro aspecto de suma importância dentro da Doutrina e que estava profundamente relacionado com a produção cultural era a noção de integração nacional que viria, tanto através da difusão da cultura em âmbito nacional, quanto pela via da eliminação dos sinais de conflito existentes dentro da sociedade brasileira daquele momento (MENDES, 2005, p. 287).
\end{abstract}

Neste cenário de exílio (Caetano e Gil vão para Londres), censura e danos psicológicos causados pela ditadura, a década de 1960 termina e, por consequência, a de 1970, com uma postura radicalizada.

Foi aí, no pós Al-5, em que o debate "cultura engajada" e "cultura alienada" começou a perder sua força; perceberam que a ideia não só era superficial, mas que a ditadura militar colocava os dois em um mesmo balaio e os restavam apenas ser sobreviventes. Restava apenas a resistência (COELHO, 2010, p. 99).

A tropicália vai além de datas. Ela não se encerra com a prisão de Caetano e Gil, mas perdura e vai além de suas primeiras predefinições (as de esvaziar e preencher o tecido cultural brasileiro, questionar o populismo nacionalista, integrar cultura popular e erudita, dentre outros). A tropicália se encontra à posteriori na marginália. A proposta de automarginalização ia além da estética ou da ideologia, se transformando em um programa de ação bem definido. A violência e a transgressão eram constantes, representações que se tornavam em um argumento criativo (COELHO, 2010, p. 175). E, por representação diz-se ação: houve uma proposta de marginalidade vivida (HOLLANDA, 1992).

A coragem para suportar foi feita visível por Rogério Duarte. A sua, a de Gil, a de Caetano, e a dos que entraram no campo de batalha. As cores da bandeira, o vermelho e o Gil militar sorridente, os gritos no palco e sua ação política. A provocação e a inquietação são figuras determinantes para esse cenário colorido, porém amargo. Afinal, mesmo quem não tem coragem para suportar, tem que arranjar também coragem pra suportar. Ou então vai embora, vai pra longe e deixa tudo ${ }^{8}$.

8 Parte da letra de "Coragem para Suportar": Ou então/ Vai embora/ Vai pra longe/ E deixa tudo/ Tudo que é nada/ Nada pra viver/ Nada pra dar/ Coragem pra suportar. 


\section{CONCLUSÃO}

Palavras derivadas dos termos "radical", "limite" e "questionamento" são recorrentes neste trabalho. Na realidade, as expressões não poderiam ser mais leves. Tratando-se de um período emblemático para o entendimento da história contemporânea do Brasil, repleta de opiniões dissonantes, momentos emblemáticos, percepções problemáticas e questionamentos dentro das mais diversas instituições - culturais, sociais, religiosas, familiares, políticas, dentre tantas outras -, só existe a possibilidade de ser radical.

O caráter deste artigo é, sobretudo, especulativo e experimental. As duas peças elencadas, que são o fio condutor deste trabalho, são notoriamente emblemáticas. Difícil falar de Rogério Duarte e Design brasileiro sem falar do cartaz do filme "Deus e o Diabo na Terra do Sol" ou de suas impressões alternativas, como a "Navilouca" ou "Flor do Mal", mas é impossível falar dele sem citar Caetano Veloso, Gilberto Gil e seus respectivos projetos gráficos de suas capas. Como no questionamento "o que é uma 'obra de valor' em história?", em que a resposta é "aquela que é situada em um conjunto operatório e que simboliza um suposto progresso em relação ao estatuto atual dos 'objetos"' (CERTEAU, 2008, p. 72), falamos de política, de repressão militar, de cultura popular, de tropicália, de música, de consumo, de juventude engajada, dentre outras discussões levantadas.

As produções de Design de Rogério Duarte fazem possível desenvolver uma reflexão sobre a cultura brasileira e a construção e consolidação do Design no Brasil, e em como, no caso da tropicália, na capacidade de difundir ideias e de se comunicar diretamente com o povo e o público consumidor dos produtos culturais da época. Primeiramente, ao considerar o recorte histórico (19641975), pensa-se a respeito de uma gama de fatores sociais, políticos e culturais. A exemplo dos mesmos e do contexto, Ortiz explica:

O crescimento da classe média, a concentração da população em grandes centros urbanos vão permitir ainda a criação de um espaço cultural onde os bens simbólicos passam a ser consumidos por um público cada vez maior. 64 inaugura um período de enorme repressão política e ideológica, mas significa também a emergência de um mercado que incorpora em seu seio tanto as empresas privadas como as instituições governamentais. Durante o período 64-80 ocorre uma formidável expansão, a nível da produção, da distribuição e do consumo de bens culturais. É nesta fase que se dá a consolidação dos grandes conglomerados que controlam os meios de comunicação de massa (TV Globo, Ed. Abril, etc.) (ORTIZ, 2006, p.83). 
É neste cenário em que o Design é instituído no Brasil a partir de uma ótica modernizante, como um "projeto de futuro" (MORAES, 2006, p. 74). Acredita-se que Rogério Duarte criou uma ruptura dentro desta crençae, a partir desta ruptura, no entendimento de que a tarefa do design é cultural (FERRARA, 1993, p. 192), visto que ele desenha e projeta informações e ideias, sua figura se torna emblemática para o entendimento do design gráfico no Brasil e seu movimento quanto a repressão, política e ideais do cenário brasileiro dos anos 1960 e 1970. 


\section{REFERÊNCIAS}

CANCLINI, Néstor García. Culturas híbridas: estratégias para entrar e sair da modernidade. São Paulo: EDUSP, 1997.

CERTEAU, Michel. A escrita da história. 2. ed. Rio de Janeiro: Forense Universitária, 2008.

COELHO, Frederico. Eu, brasileiro, confesso minha culpa e meu pecado. Rio de Janeiro: Civilização Brasileira, 2010.

COHN, C. Antropologia da criança. Rio de Janeiro: Jorge Zahar Ed.2005; 60 pp

CONY, Carlos Heitor. O ato e o Fato. São Paulo: Nova fronteira,1964

D'ARAÚJO, Maria Celina; SOARES, Gláucio. 21 anos de regime militar: balanços e perspectivas. Rio de Janeiro: FGV, 1994.

DUARTE, Rogério. Notas sobre desenho industrial. Revista Civilização Brasileira, Rio de Janeiro, n. 4, 1965.

DUNN, Christopher. Brutalidade jardim: a tropicália e o surgimento da contracultura brasileira. São Paulo: Unesp, 2009.

FARTHING, Steven. Tudo sobre arte. Rio de Janeiro: Sextante, 2010.

FAVARETTO, Celso. Tropicália: alegoria, alegria. São Paulo: Kairós, 1979.

FERRARA, Lucrecia D 'Alessio. Olhar periférico. São Paulo: Edusp, Fapesp, 1993.

HARVEY, David. A condição pós-moderna: uma pesquisa sobre as origens da mudança cultural. São Paulo: Loyola, 2001.

HOLLANDA, Heloisa Buarque. Impressões de viagem: CPC, vanguarda e desbunde. Rio de Janeiro: Rocco, 1992.

IANNI, Octávio. A ideia do Brasil moderno. 2. ed. São Paulo: Brasiliense, 1996.

MANIFESTO nacional pela democracia e o desenvolvimento. Correio da Manhã, Lisboa, 14 mar. 1965.

MARCUSE, Herbert. Eros e civilização: uma interpretação filosófica do pensamento de Freud. 6. ed. Rio de Janeiro: Zahar, 1966. 
MATTOS, Narlan (Org.). Tropicaos. Rio de Janeiro: Azougue Editorial, 2003.

MELLO, Chico Homem. O design gráfico brasileiro: anos 60. São Paulo: Cosac Naify, 2006.

MENDES, Ricardo Antonio Souza. Cultura e repressão nos tempos do Al-5. In: MUNTEAL FILHO; FREIXO, Adriano de; FREITAS, Jacqueline Ventapane. (Orgs.). Tempo negro, temperatura sufocante: estado e sociedade no Brasil do Al-5. Rio de Janeiro: Ed. PUC-Rio; Editora Contraponto, 2005 MITCHELL, William John Thomas. O que as imagens realmente querem? In: ALLOA, Emmanuel. Pensar a imagem. Belo Horizonte: Autêntica, 2015.

MORAES, Dijon. Análise do design brasileiro: da mimese à mestiçagem. São Paulo: Blucher, 2006.

NAPOLITANO, Marcos. Coração civil: arte, resistência e lutas culturais durante o regime militar brasileiro (1964-1980). 2011. 374 f. Tese (Doutorado em História do Brasil Independente) - Universidade de São Paulo, São Paulo, 2011.

NAPOLITANO, Marcos. Cultura brasileira: utopia e massificação (1950-1980). São Paulo: Contexto, 2001.

NAPOLITANO, Marcos. Seguindo a canção: engajamento político e indústria cultural na MPB (1959-1969). São Paulo, 2010.

NAPOLITANO, Marcos. Tropicalismo: as relíquias do Brasil em debate. Revista Brasileira de História, São Paulo, v. 18, n. 35, 1998.

NAVES, Santuza Cambraia. Da bossa nova à tropicália. São Paulo: Zahar, 2001.

ORTIZ, Renato. A moderna tradição brasileira. Belo Horizonte: Brasiliense, 1988.

ORTIZ, Renato. Cultura brasileira e identidade nacional. 5. ed. São Paulo: Brasiliense, 2006.

RANCIÈRE, Jacques. As imagens querem realmente viver?. In: ALLOA, Emmanuel. Pensar a imagem. Belo Horizonte: Autêntica, 2015.

RODRIGUES, Jorge Caê. Anos fatais: design, música e tropicalismo. Rio de Janeiro: 2AB, 2007.

SANTOS, Nelyane; VIVAS, Rodrigo. Questionamentos sobre as relações de condicionalidade entre proposições artísticas e o contexto político do Brasil na década de 1960 nas obras dos Salões Municipais de Belas Artes da Prefeitura 
de Belo Horizonte. In: SEMINÁRIO 1964-2014: UM OLHAR CRÍTICO, PARA NÃO ESQUECER UFMG, 2014, Belo Horizonte. Anais... Belo Horizonte, 2014.

TEIXEIRA, Narlan Matos. Inventário do caos: Rogério Duarte, tropicália e pós- modernidade. 2012. 260 f. Tese (Doutorado em Filosofia) - University of Illinois at Urbana-Champaign, Urbana, 2012.

TORQUATO NETO. Verbo desencantado. Jornal O Dia, Teresina, 18 jun. 1972. Domincultura.

VELOSO, Caetano. Verdade tropical. São Paulo: Companhia das Letras, 1997.

VENTURA, Zuenir. 1968: o ano que não terminou. Rio de Janeiro: Nova Fronteira, 1988.

VILLAS-BOAS, André. O que é (e o que nunca foi) design gráfico. 6. ed. São Paulo: 2AB, 2000.

WONG, Wucius. Princípios de forma e desenho. 2. ed. São Paulo: Martins Fontes, 2001.

XAVIER, Ismail. Alegorias do subdesenvolvimento. São Paulo: Cosac Naify, 2012. 